\title{
A1- and $A 2$ beta-casein on health-related outcomes: a scoping review of animal studies
}

\author{
Daniela Kuellenberg de Gaudry ${ }^{1}$ (1) $\cdot$ Szimonetta Lohner ${ }^{2} \cdot$ Karin Bischoff $^{1} \cdot$ Christine Schmucker $^{1}$. \\ Simone Hoerrlein ${ }^{3} \cdot$ Christine Roeger $^{3} \cdot$ Lukas Schwingshackl $^{1} \cdot$ Joerg J. Meerpohl ${ }^{1}$
}

Received: 7 October 2020 / Accepted: 30 March 2021 / Published online: 1 June 2021

(c) The Author(s) 2021

\begin{abstract}
Purpose Food-derived bioactive peptides may influence important physiological functions. An important example is betacasomorphins, which are opioid peptides derived from A1 beta-casein in bovine milk and have been associated to be risk factors for non-communicable diseases in humans. A1 and A2 beta-casein are different with respect to the release of bioactive peptides, in particular BCM-7. However, evidence from human studies is limited and could be complemented with evidence derived from animal studies. We conducted a scoping review to identify animal studies investigating the effects of A1 betacasein or BCM-7 compared to A2 beta-casein or any other intervention on health-related outcomes.

Methods We systematically searched for relevant studies in two electronic databases (Medline, Embase; last search performed March 2020). Two reviewers independently undertook study selection and data extraction of included references. Results were summarized tabularly and narratively.

Results We included 42 studies investigating various animal models, including rats, mice, rabbits, and dogs. Six studies investigated health-related outcomes of A1- vs. A2 milk, while most studies $(n=36)$ reported on physiological properties (e.g., analgesic effect) of BCM-7 as an opioid peptide. Included studies were extremely heterogeneous in terms of the study population, type of intervention and dose, and type of outcome measures.

Conclusions Only a few studies comparing the effects of A1- and A2 milk were identified. More studies addressing this research question in animal models are needed to provide essential information to inform research gaps. Results from future studies could eventually complement research for humans, particularly when the body of evidence remains uncertain as is the case in the A1- and A2 milk debate.
\end{abstract}

Keywords A1 beta-casein $\cdot$ A1-milk $\cdot$ A2-milk $\cdot$ Beta-casein $\cdot$ Animal studies

\section{Background}

Proteins are a broad family of organic compounds with an important role in the structure and functionality of all living organisms [1]. They are a fundamental component of animal and human diets providing a source of energy, nitrogen, and

Joerg J. Meerpohl

meerpohl@cochrane.com

1 Institute for Evidence in Medicine, Medical Center University of Freiburg, Faculty of Medicine, University of Freiburg, Breisacher Str. 153, 79110 Freiburg, Germany

2 Cochrane Hungary, Clinical Center, Medical School, University of Pécs, Pecs, Hungary

3 Competence Center for Nutrition, Bavarian State Ministry for Food, Agriculture and Forestry, Freising, Germany essential amino acids [1]. In addition, dietary proteins may also provide a source of biologically active peptides, which are inactive within the sequence of the precursor protein but may become active when released by hydrolysis during food processing [1]. Food-derived bioactive peptides may influence physiological functions, including modulation of gut secretion and motility, blood pressure, thrombotic, antioxidant, antimicrobial, and immunomodulatory activities [1]. Some of these effects are mediated by interaction with the opioid system and are therefore called opioid peptides.

Opioid peptides can be formed from milk, cereal, vegetables, and meat/poultry. The most investigated so far are the ones derived from bovine milk [1]. Approximately one-third of bovine milk proteins are beta-caseins, which are present in various genetically determined forms in milk, including the $\mathrm{A} 1$ and $\mathrm{A} 2$ variants. Milk free of A1 beta-casein 
is commonly known as A2 milk, which contains mostly A2 beta-casein with a possible caveat of minor contamination. All other bovine milk is commonly referred as to A1 milk, which contains predominantly A1 beta-casein. Both milk types have shown to have different digestive results. In contrast to the $\mathrm{A} 2$ milk, digestion of $\mathrm{A} 1$ milk releases beta-casomorphin 7 (BCM-7), which is a potent opioid peptide influencing the above-mentioned physiological effects [2]. Thus, BCM-7 is thought to be responsible for potential adverse outcomes in humans, such as the increased risk of diabetes [3]. In contrast, the consumption of milk containing exclusively the A2 beta-casein variant (A2 milk) has been promoted as being associated with positive health effects in humans, including reduced gastrointestinal symptoms [4].

We recently published a systematic review about the health effects of A1 milk reported in human studies and found some evidence suggesting beneficial gastrointestinal effects of A2 milk compared to A1 milk [5]. However, implications of A1 beta-casein on other health-related outcomes were limited and were graded with low or very low certainty of evidence. In contrast, various animal studies suggest that opioid peptides like BCM-7 could have even beneficial physiological properties [2].

The main objective of this scoping review was to identify and describe all primary studies evaluating health-related outcomes of A1 beta-casein consumption/exposure in animal models.

\section{Materials and methods}

This scoping review was conducted following the methods from the Cochrane Handbook for systematic reviews of interventions [6], and following recommendations from the SYRCLE (Systematic Review center for Laboratory Animal Experimentation) method group [7]. Methods for the scoping review were defined a priori in a protocol (not registered). The methodology and the results are reported according to the PRISMA guidelines for scoping reviews [8] (see additional file 1).

\section{Eligibility criteria}

The research question was defined according to the PICO approach (Participants, Interventions, Comparison, Outcomes). We included studies investigating A1 beta-casein or BCM-7 intake (independently of the method of administration, e.g., orally or given through injection) on any healthrelated outcome in animals (e.g., gastrointestinal markers such as gastrointestinal transit time (GITT), incidence of diabetes, intermediate disease markers of CVD such as LDL and HDL concentrations, etc.). Any comparison intervention (including $\mathrm{A} 2$ beta-casein, other BCM-fractions, etc.) was considered eligible, and included studies had to report on a health-related outcome. No restrictions on study design were applied. Studies published in a language other than English, Spanish, German, or French; or studies without a full-text (i.e., abstracts) were excluded, but listed in a separate table. Studies in which the intervention was given to deceased animals were excluded.

\section{Systematic literature search}

To identify all published studies investigating A1 beta-casein on health-related outcomes in animals, we searched Medline (PubMed) and Embase from inception until February 2017. An update search was performed in March 2020. The search strategy was constructed using free text and MeSH terms (or EMTREE). To identify animal studies, the recommended filters from SYRCLE for both databases were used $[9,10]$. Search strategies are presented in the supporting information (see additional file 2). Additionally, reference lists of eligible articles were screened for further relevant references.

\section{Study selection}

Each reference was screened by two reviewers independently from each other (SL, DK, and KB) based on predefined inclusion criteria using the Covidence online software [11] in dual screening mode, i.e., each reference had to be screened by two of the three reviewers-the assignment of references is aleatory. First, titles and abstracts of studies retrieved through the searches were screened to exclude obvious irrelevant references. Second, full publications of potentially relevant studies were obtained and checked for final inclusion. Any disagreement was resolved through consensus.

\section{Data extraction}

Data from each included reference were extracted by two reviewers independently from each other (DK, SL and $\mathrm{KB}$-references were assigned aleatory to each reviewer by reference ID number), and any disagreement was resolved through consensus.

The following data were extracted for each included study: bibliographic details, study characteristics [incl. objective(s), details of funding, study design, number of animals included], characteristics of the included animals (incl. age, gender, animal species, breeding, housekeeping- and acclimatisation conditions), characteristics of the intervention and control intervention (incl. type, dosage, and mode of administration), and outcome data (incl. definition, time of measurement). 
Fig. 1 PRISMA flow diagram of systematic literature search

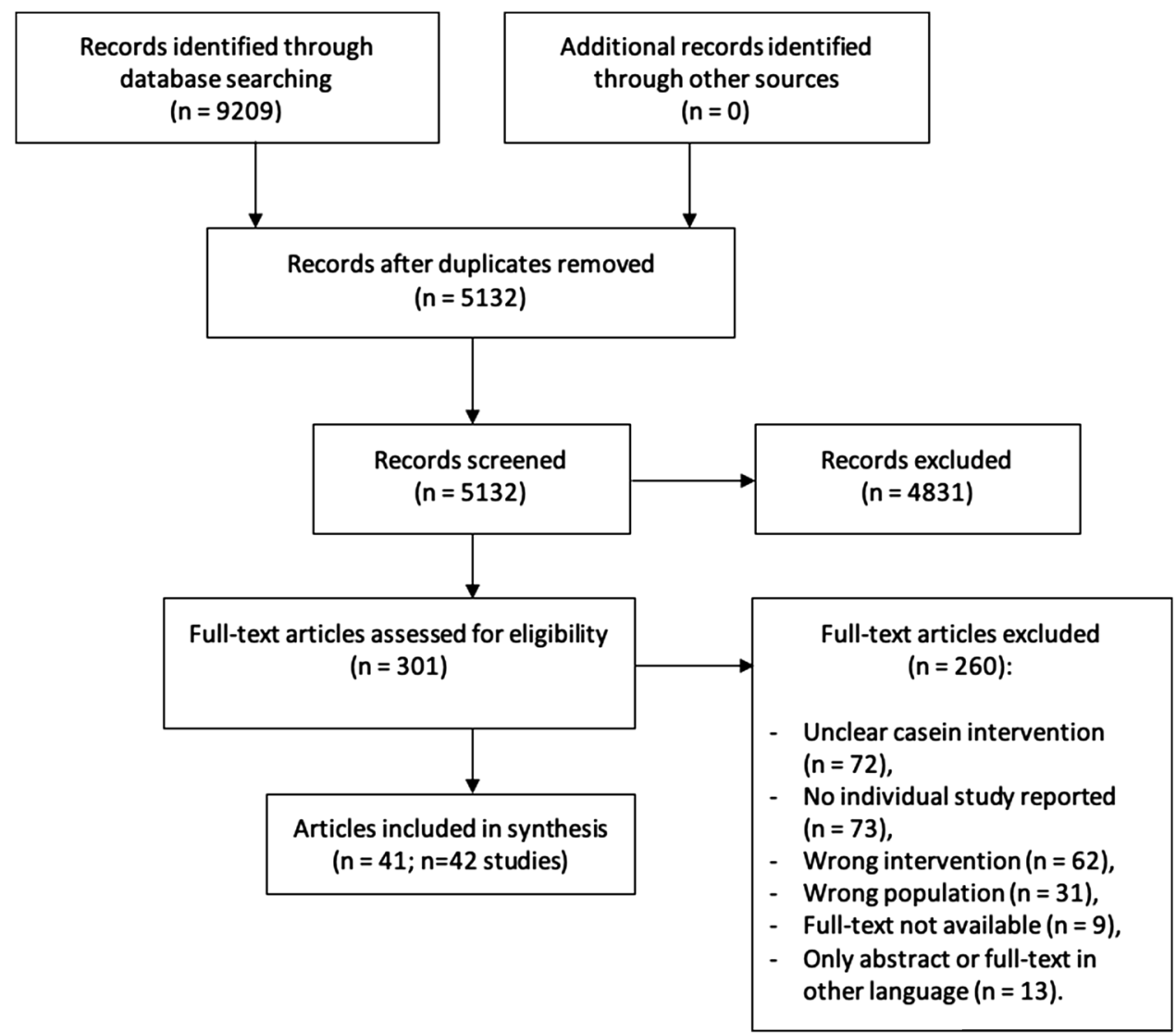

\section{Data synthesis}

Results from this scoping review were summarized in bubble charts and in tables with relevant information on each included study. Results were also described narratively.

\section{Results}

\section{Results of the search}

During the systematic literature search in both electronic databases, we identified 9209 potentially relevant records. After removing duplicates, 5132 unique records were assessed for eligibility. From these, 4831 records were excluded after title- and abstract screening and 260 after full-text screening. Finally, 41 records fulfilled our inclusion criteria (Fig. 1). From these, one reference reported results of two studies, therefore, 42 studies were included in this scoping review. Additionally, 14 records were excluded from data extraction, because they were published in other language, were not published as full texts, or full texts were not available (these references are listed in additional file 3 ).

\section{Description of included studies}

A total of 42 trials were included in this scoping review. Six from the included studies evaluated A1- vs. A2 beta-casein, and the remaining 36 studies analysed BCM-7 vs. various control interventions, incl. other protein fragments (mainly shorter BCM fragments), distilled water or saline solution. Results of this scoping review are displayed for each of these two comparisons separately and can be found in Tables 1 , 2 respectively.

\section{Characteristics of studies comparing A1- vs. A2 beta-casein}

From the six studies evaluating A1- vs. A2 beta-casein, most studies were performed monocentric in Australia, Poland, India, UK; and one study was carried out as multicentric in New Zealand, Canada, and the UK [12]. At least 723 animals were investigated in all studies together (min 6 animals and max 585 animals per study; one study did not report the number of animals included [13]). The animal population consisted of rats $(n=3397)$, mice $\left(n=339^{1}\right)$, pigs $(n=6)$, and rabbits $(n=60)$. Animals received the intervention

\footnotetext{
1 This is underestimated, since two studies provided no information
} on the number of animals included. 


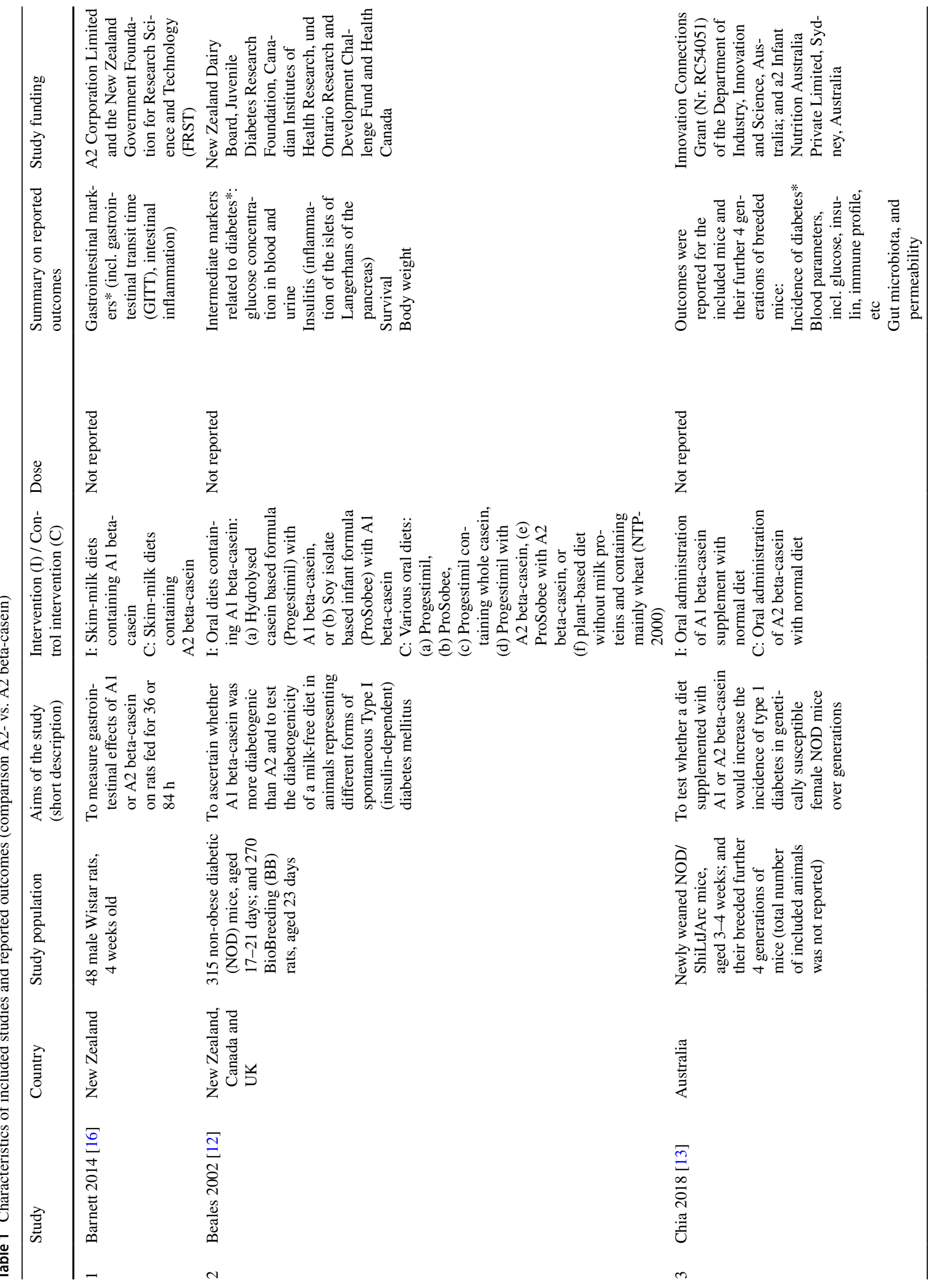




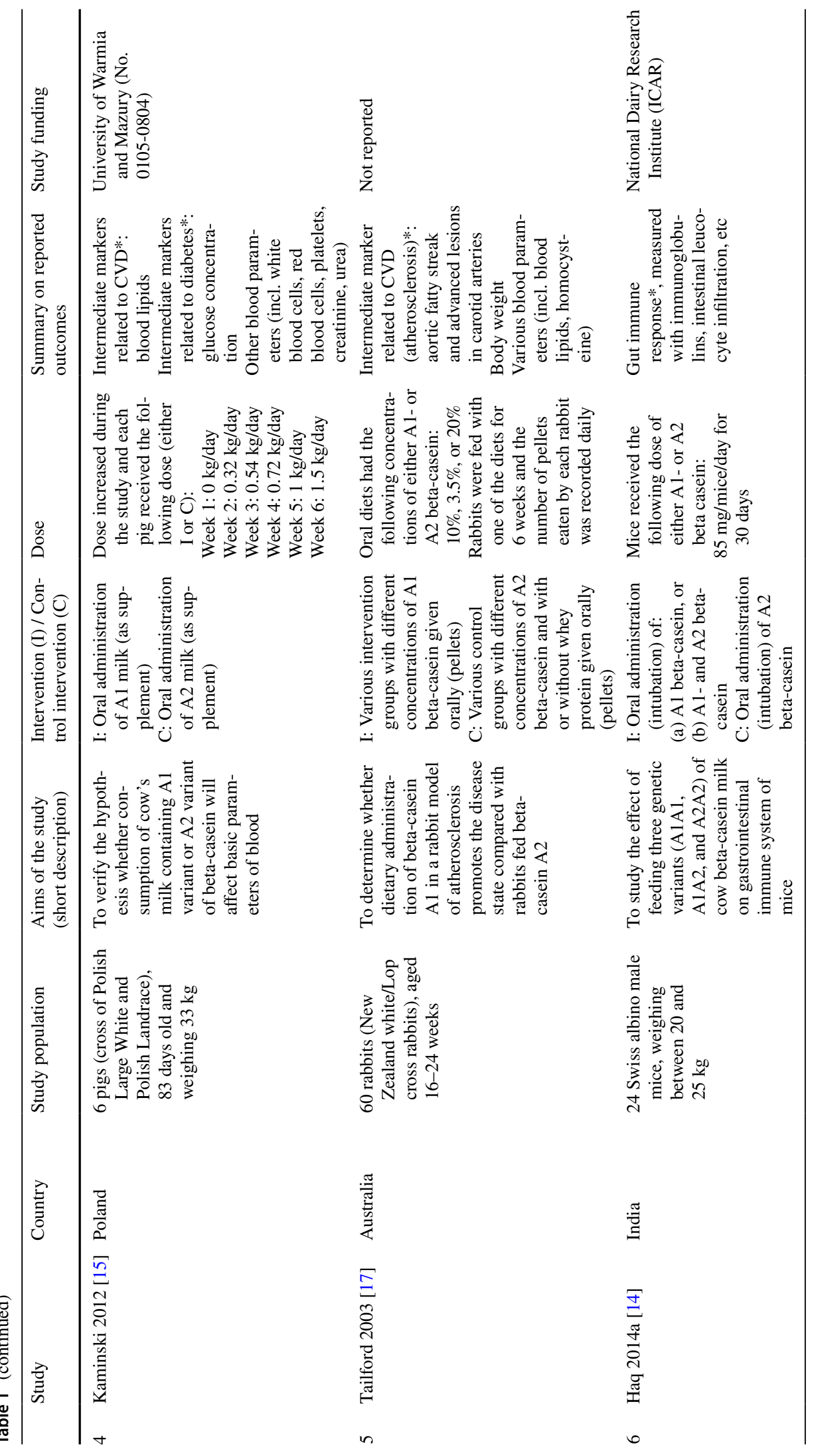




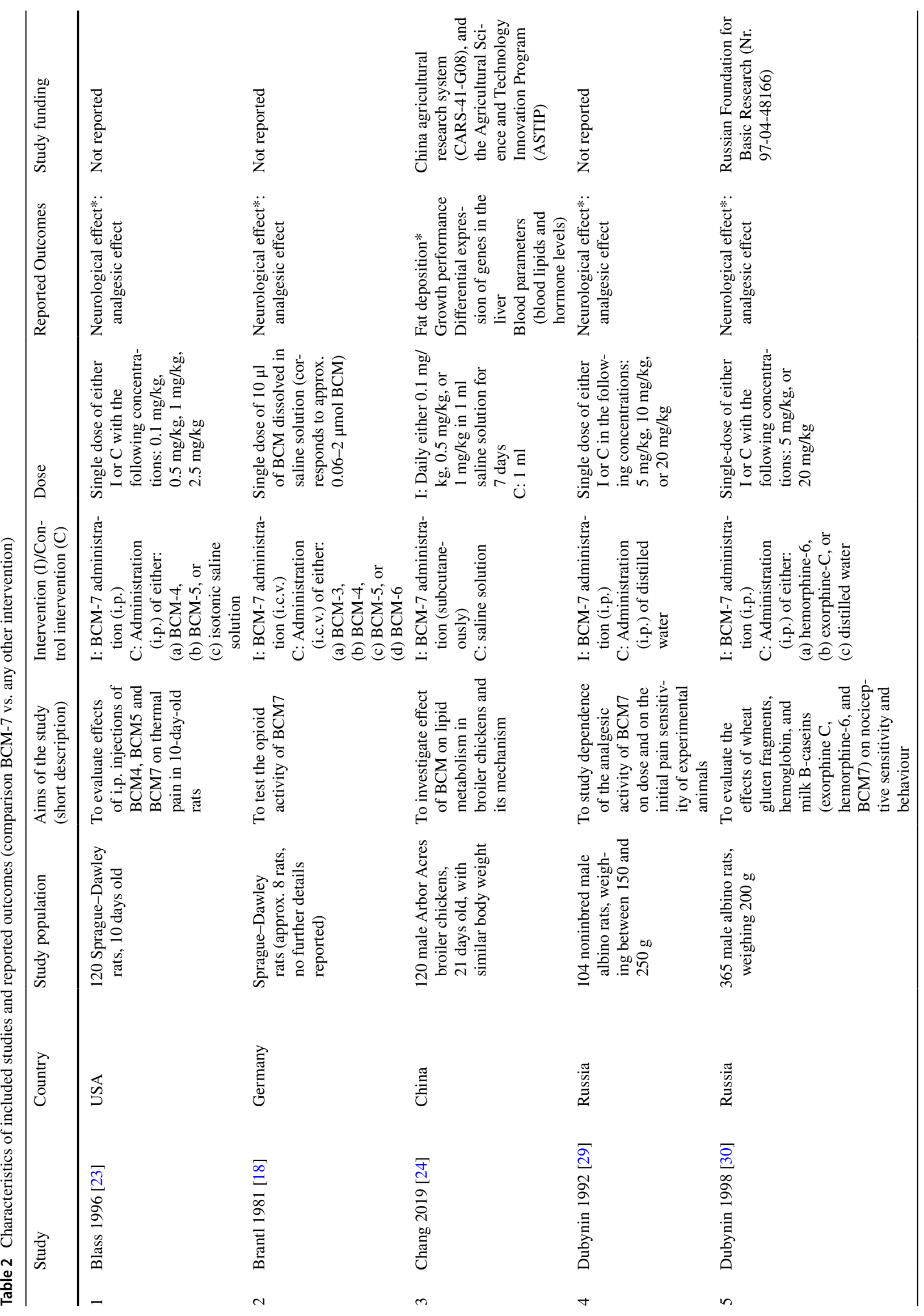




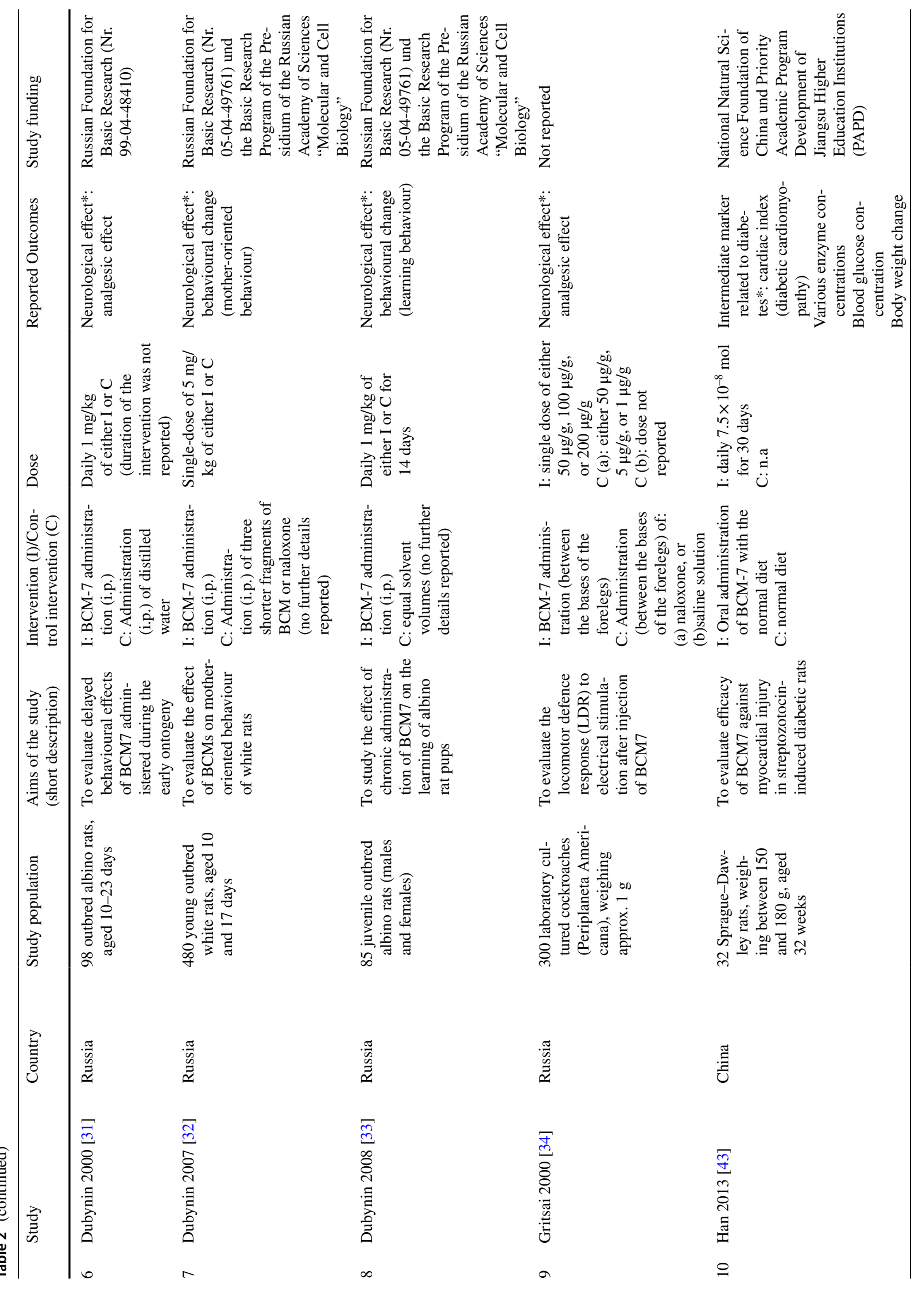




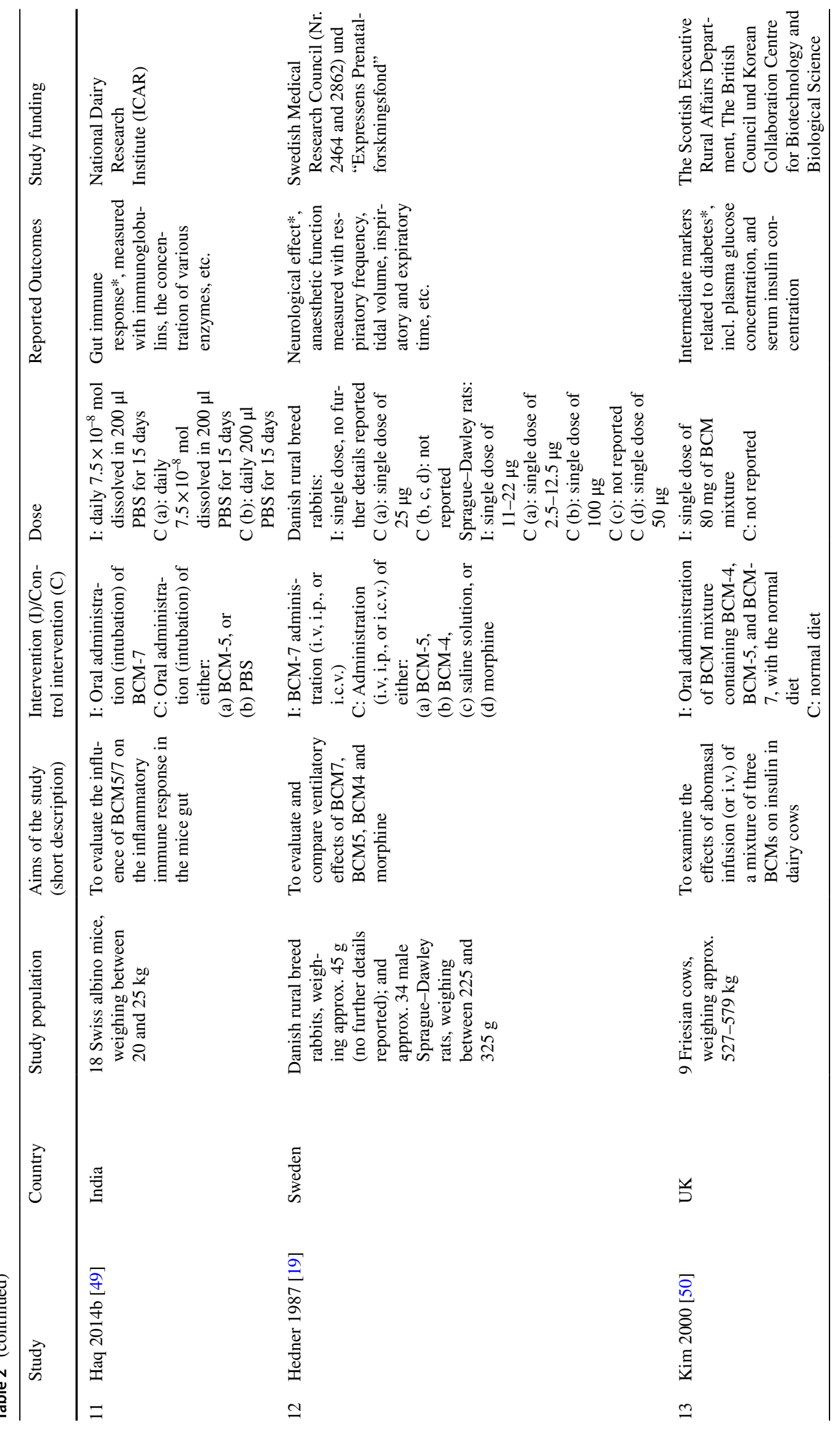




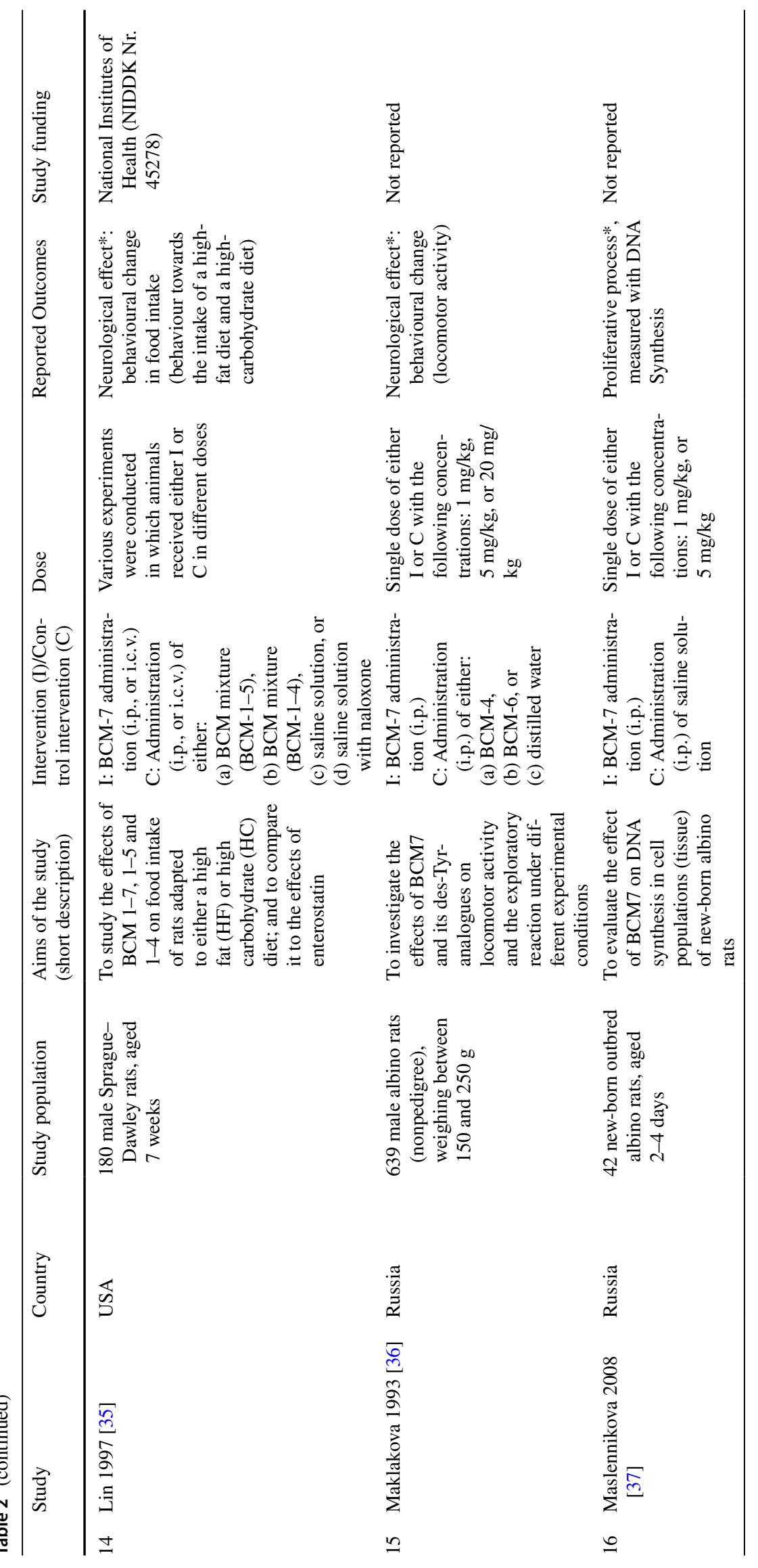




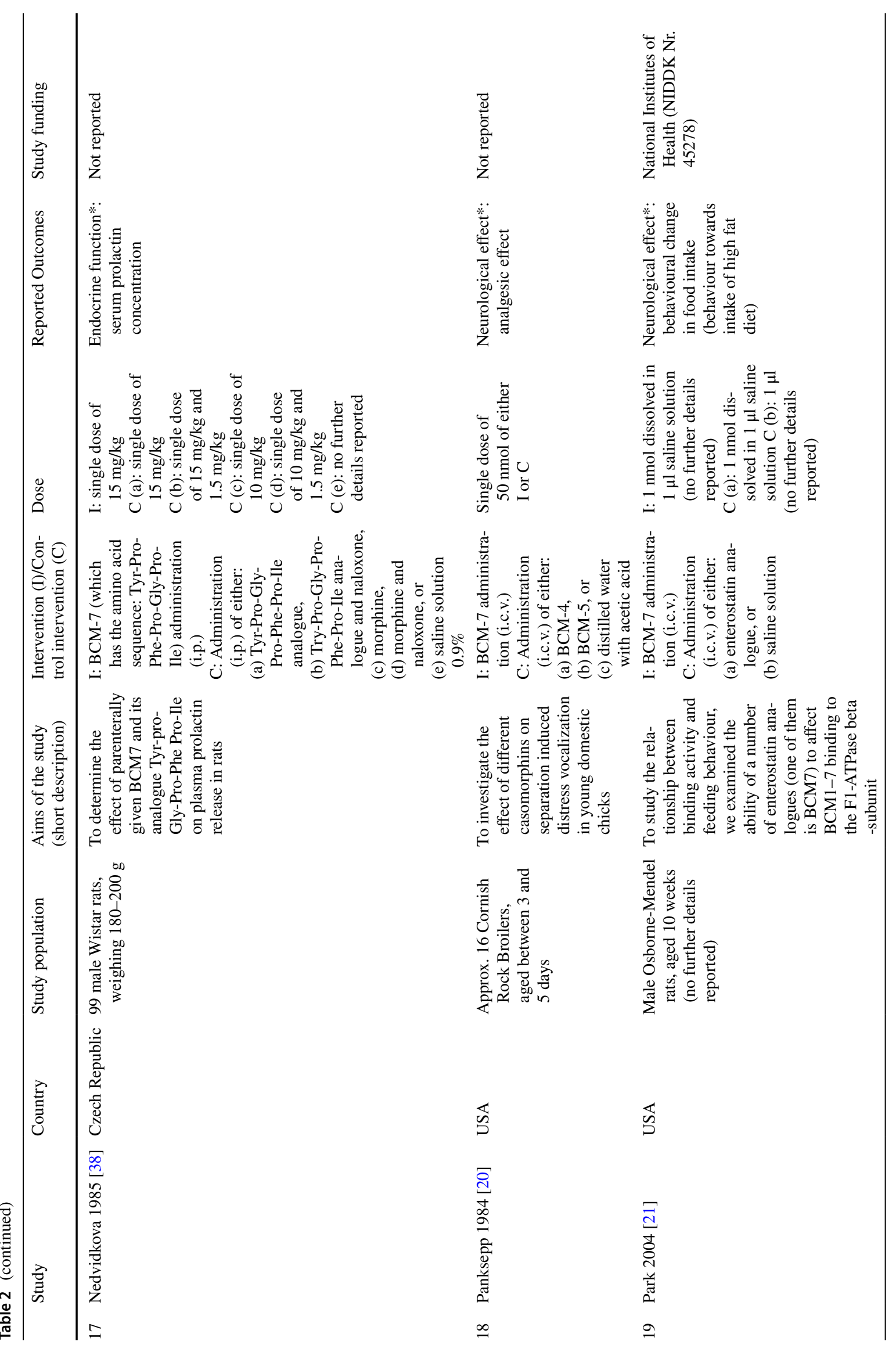




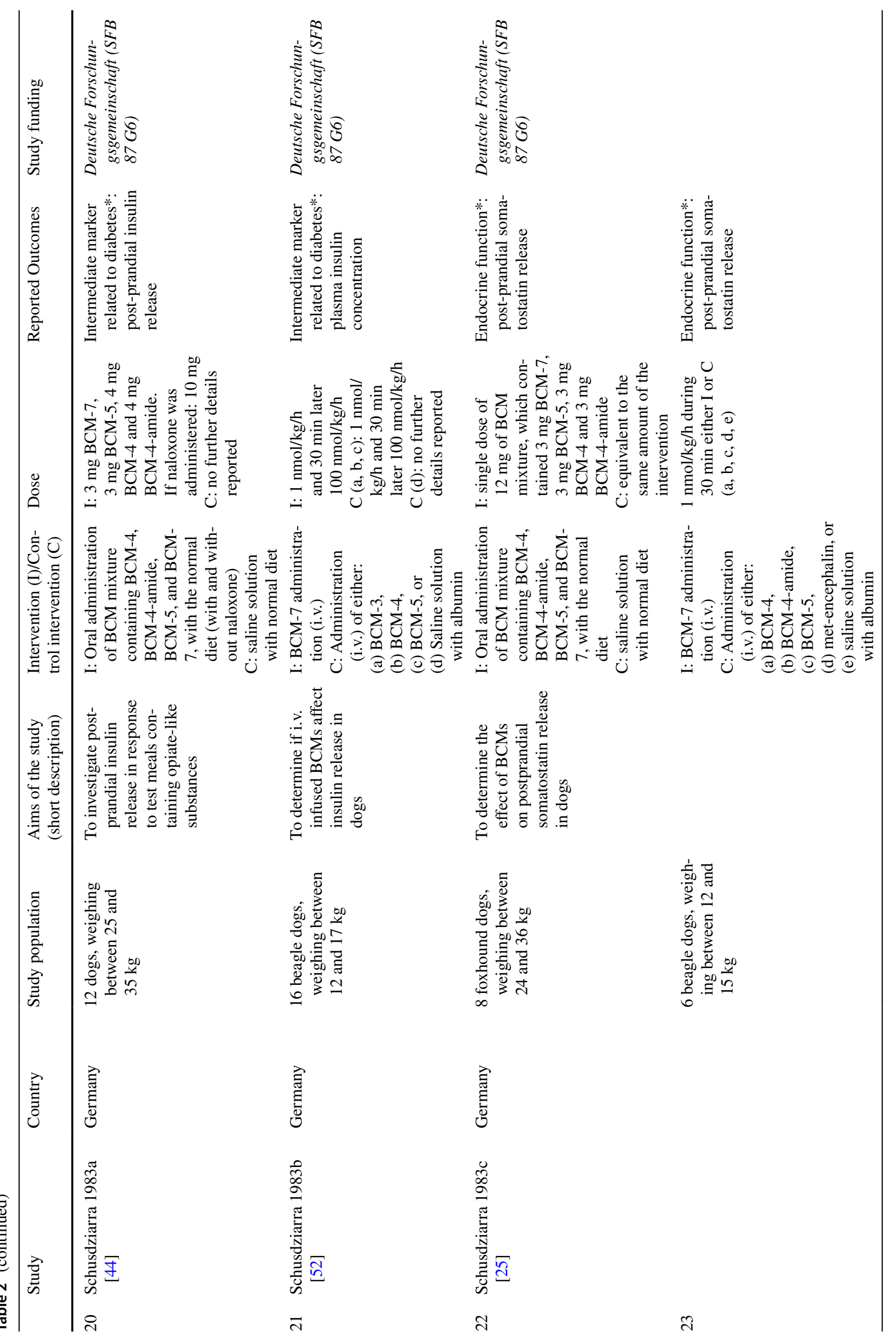




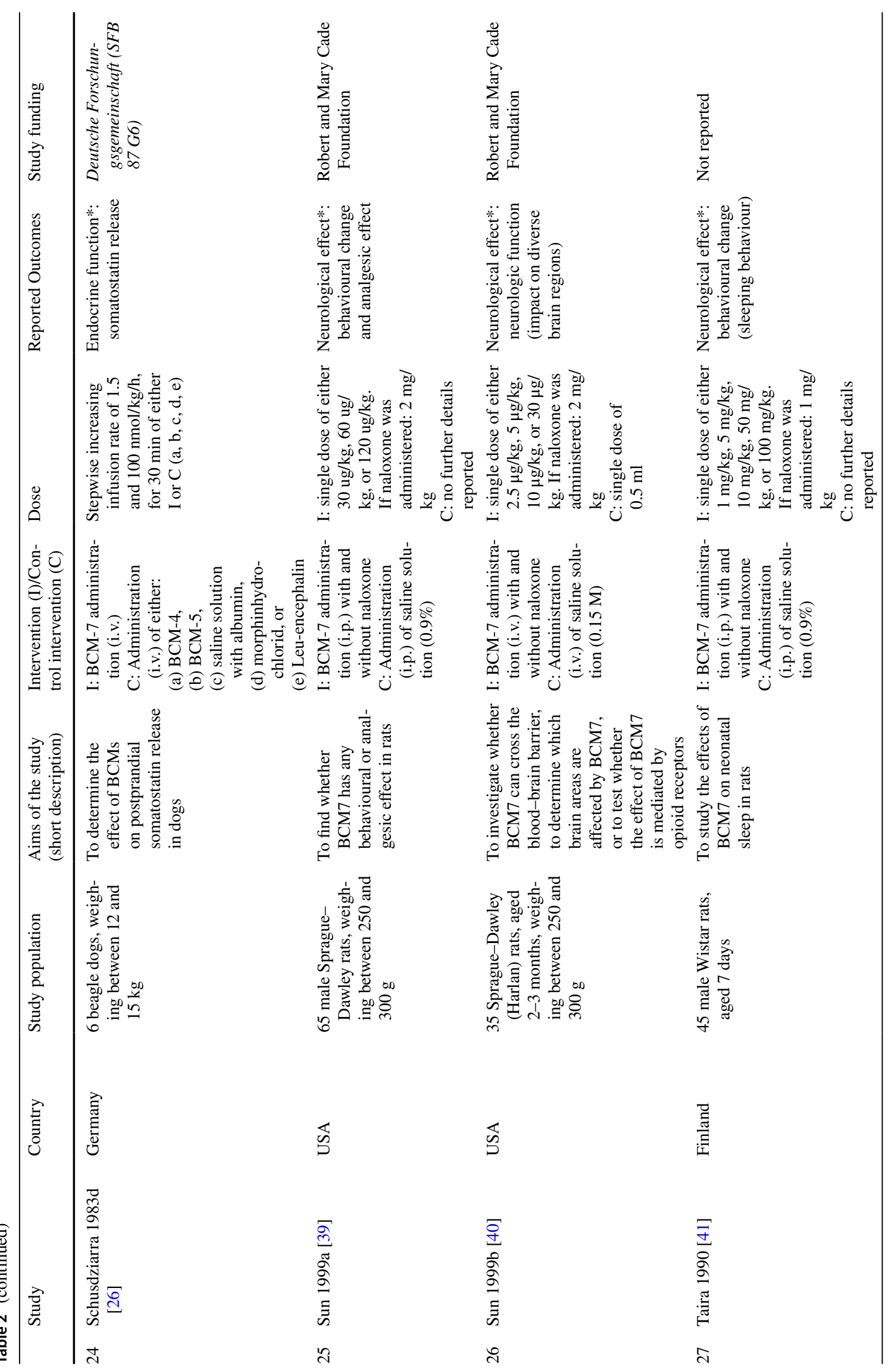




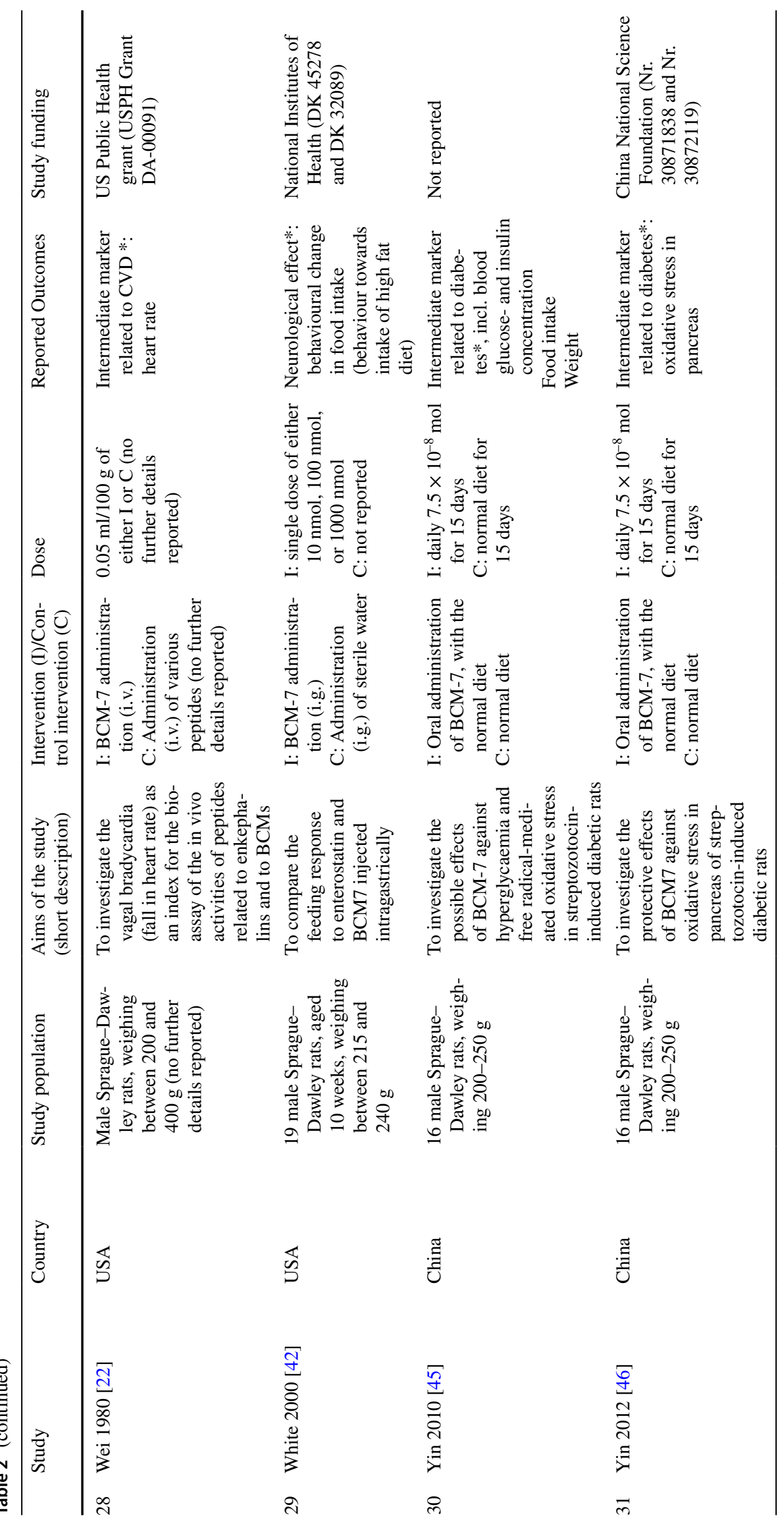




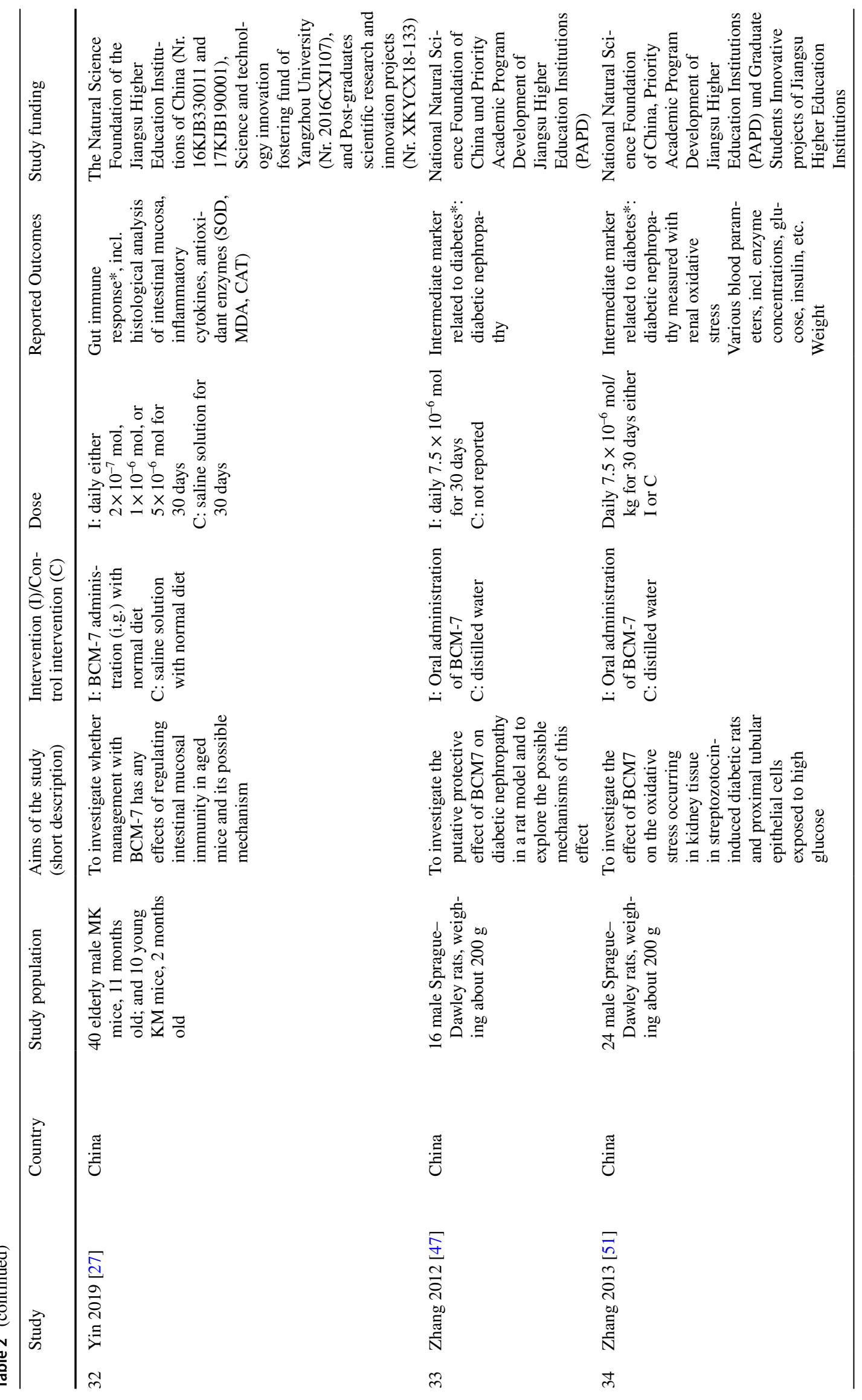




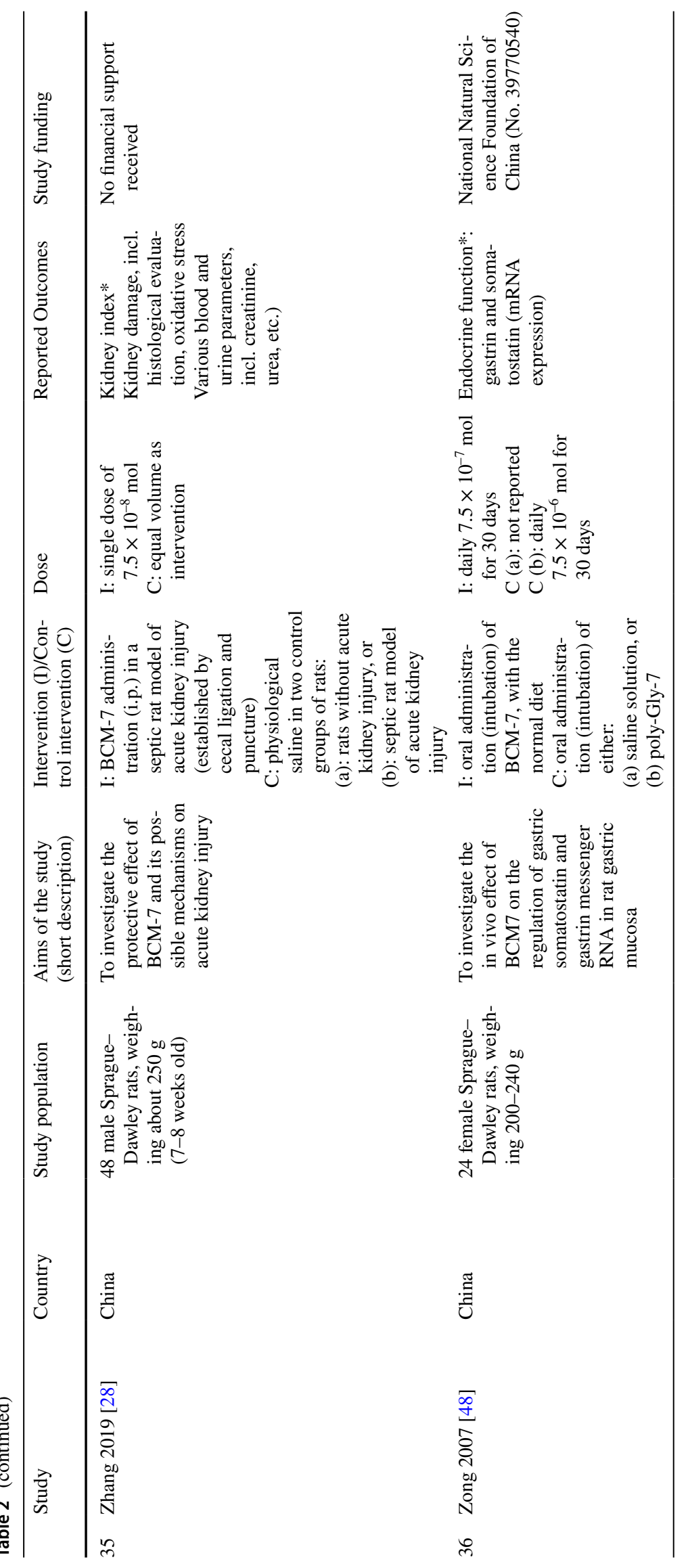


or control intervention orally, mainly supplemented with their normal diet. One study administered the intervention through intubation [15]. The intervention was either A1 milk or A1 beta-casein, whereas the control intervention was A2 milk or A2 beta-casein respectively. The analysed outcomes included gastrointestinal markers and various intermediate markers of diabetes and CVD, including blood glucose and insulin concentrations, blood lipids, and markers of atherosclerosis (i.e., aortic fatty streak and advanced lesions in carotid arteries). Outcomes were measured in living or deceased animals depending on the nature of the outcome (i.e., lipid profile was measured in living animals, bowel inflammation status after bowel resection was measured in deceased animals).

Three studies were financially supported exclusively by independent funding agencies or research institutes $[12,14$, 15], two studies reported the a2 Milk Company Limited (formerly A2 Corporation) as sponsor $[13,16]$, and one study provided no information on funding [17].

All study characteristics can be found in Table 1 .

\section{Characteristics of studies comparing BCM-7 vs. any other intervention(s)}

Thirty-six studies comparing the effects of BCM-7 with other interventions were included. Study characteristics are listed in Table 2. Briefly, all studies were performed monocentric in various countries worldwide, incl. USA, Germany, Russia, and China. The animal population consisted mainly of rats, but also mice, rabbits, cows, broilers, dogs, and cockroaches were analysed. All studies included at least 3154 animals in total (min 6 animals and max 639 animals per study; five studies did not report the exact number of animals included [18-22]). Most studies administered BCM-7 as injection [18-25, 25-42] and ten studies administered it orally [25, 43-51]. Most studies provided BCM-7 alone, whereas three studies used a mix of BCM-fragments (including BCM-7) as intervention [25, 44, 50]. The control interventions were saline solution, distilled water, various proteins (e.g., exorphins and encephalin), or shorter BCMfragments (e.g., BCM-3, -4, -5). Included studies had mainly an explorative focus on investigating biological effects of BCM-7 (quantitatively and qualitatively) and had no primary interest in comparing BCM-7 with other interventions. Therefore, outcomes measured across studies varied greatly, e.g., pain relief, behavioural change, intermediate markers of diabetes and neurologic functions, various blood parameters (incl. parameters of immune function, enzyme concentrations), etc.

Most studies $(n=25)$ were supported by different independent funding agencies or research institutes, ten studies provided no information on funding [18, 20, 23, 29, 34,
36-38, 41, 45], and one study reported that no funding was received [28].

\section{Health-related outcomes}

Included studies reported on various types of outcomes and most of them were either intermediate markers of a disease or a condition or were measured to describe a physiologic process.

Outcomes investigated across included studies are displayed in bubble charts and described narratively.

\section{Details of interventions and health-related outcomes in studies comparing $A 1$ - vs. $A 2$ beta-casein}

Figure 2 shows a bubble chart with the primary outcomes reported in studies comparing A1- with A2 beta-casein. Outcomes are grouped according to the animal model in which they were investigated.

Two studies reported on the following intermediate markers of cardiovascular disease (CVD): blood lipids and aortic fatty streak and lesions in carotid arteries [15, 17]. Tailford et al. reported on significantly fewer aortic fatty streaks formation (as marker of atherogenic effect) in rabbits who were given $\mathrm{A} 2$ beta-casein, compared to rabbits under the oral administration of A1 beta-casein [17]. Kaminski et al. found no significant difference in total cholesterol- and triacyglcerols) after A1- or A2 beta-casein administration in pigs [15].

The incidence of diabetes was investigated in four consecutive generations of NOD mice fed with either A1- or A2 beta-casein in the study of Chia et al. [13]. They found that dietary A1 beta-casein increased diabetes incidence in the 3rd and 4th generation of mice, whereas incidence did not change in previous generations [13]. Glucose concentration in blood or urine was investigated in two studies $[12,15]$. Authors reported no difference in the glucose concentration in mice and pigs after the administration of A1- or A2 beta-casein $[12,15]$, whereas a favourable effect of A2 betacasein compared to A1 beta-casein was observed in the rat population [12].

Furthermore, one study analysed gastrointestinal effects in rats and found that dietary A2 beta-casein administration caused reduced intestinal inflammation and a favourable gastrointestinal transit time compared to the $\mathrm{A} 1$ beta-casein intervention [16]. Similarly, Haq et al. found a favourable gut immune response in mice fed $\mathrm{A} 2$ beta-casein, compared to mice fed A1 beta-casein (or A1/A2 beta-casein) [14].

None of the included studies investigating A1 vs. A2 beta-casein measured the level of BCM-7, which could provide a link between $\mathrm{A} 1$ beta-casein and the release of this bioactive peptide. 


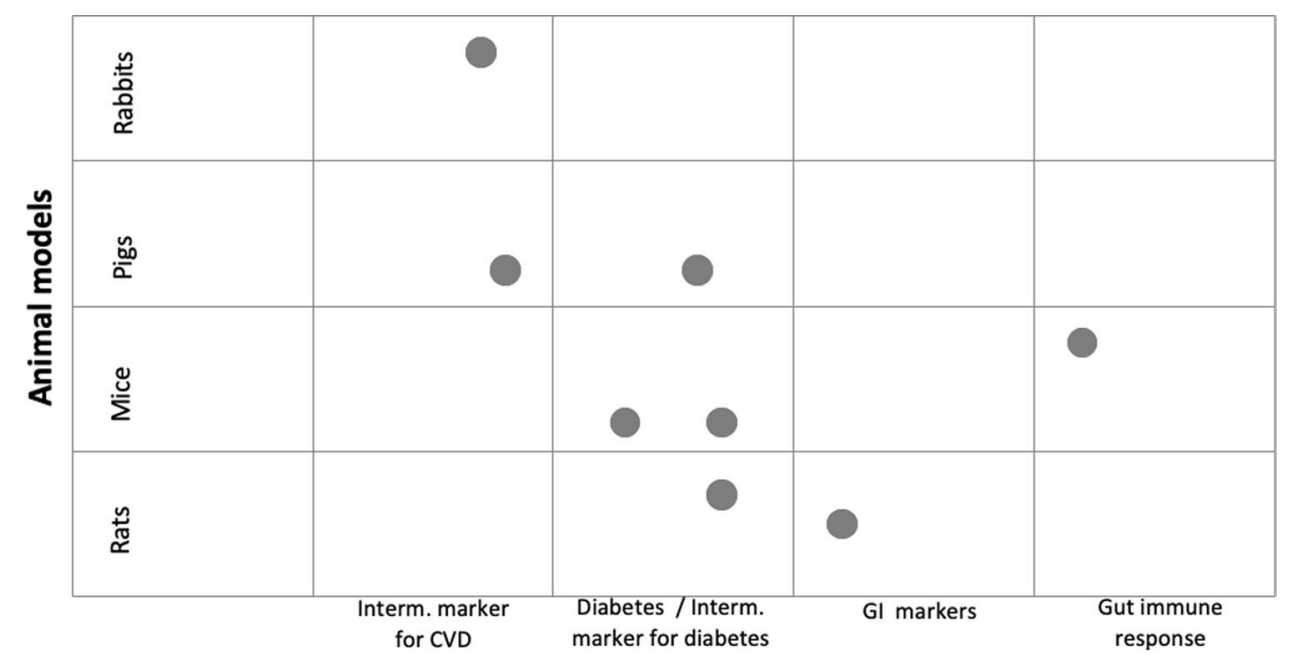

Fig. 2 Bubble chart of studies comparing A1- vs. A2 beta-casein. $C V D$ cardiovascular, GI gastrointestinal. Each dot in the bubble chart represents the primary outcome investigated in the included studies, which are marked with an $\left(^{*}\right)$ in Table 1 (i.e., Interm. marker for CVD: blood lipids, aortic fatty streak and lesions in carotid arteries; Diabetes/Interm. marker for diabetes: incidence of diabetes, glucose concentration in blood and urine; GI markers: gastrointestinal transit time and intestinal inflammation; Gut immune response: concentration of immunoglobulins). If a study investigated the primary outcome in more than one animal model, the chart shows a dot for each animal model (i.e., Beales 2002 [12], Kaminski 2012 [15])

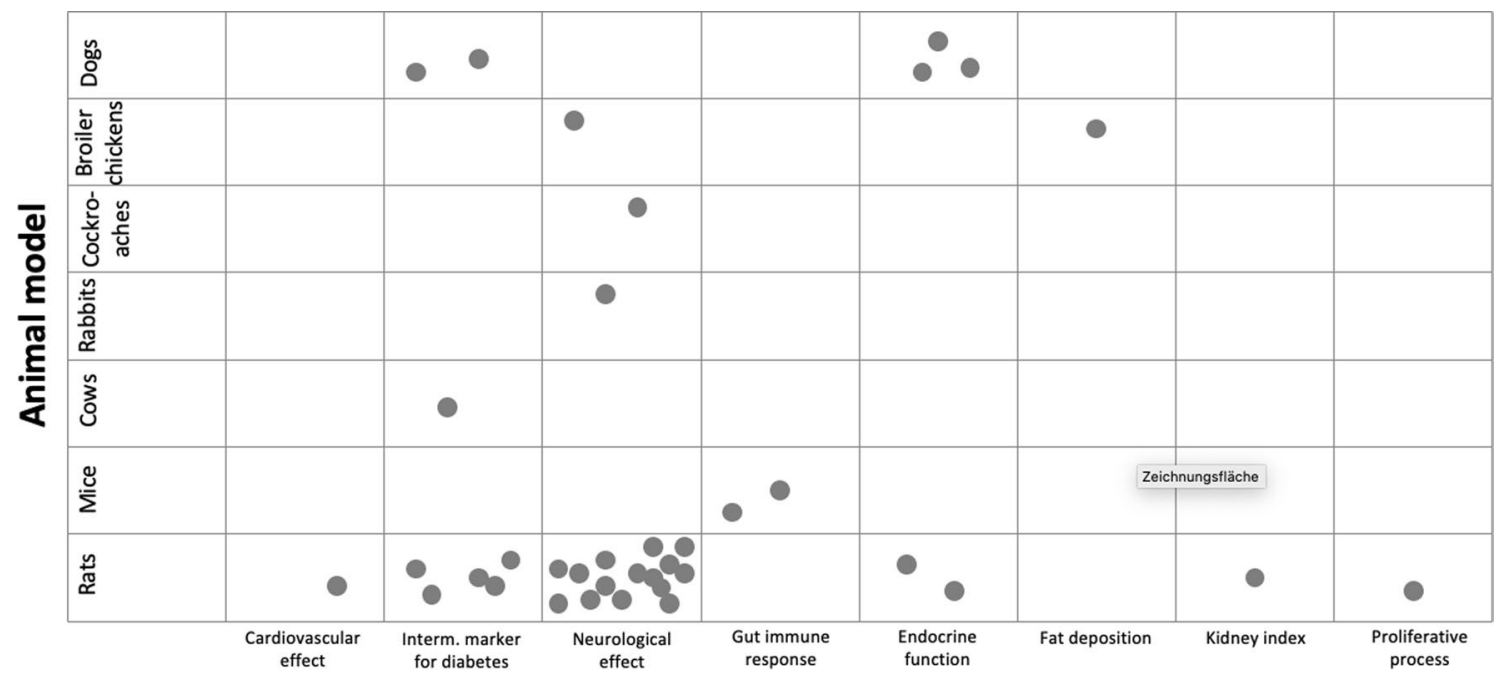

Fig. 3 Bubble chart of studies comparing BCM-7 vs. any other intervention. Each dot in the bubble chart represents the primary outcome investigated in the included studies, which are marked with an (*) in Table 2 (i.e., intermediate marker for CVD: heart rate; Interm. marker for diabetes: diabetic cardiomyopathy, glucose and insulin concentration, pancreatic oxidative stress, diabetic nephropathy; Neurological

\section{Details of interventions and health outcomes in studies comparing BCM-7 vs. any other intervention(s)}

Figure 3 shows a bubble chart with the primary outcomes reported in studies comparing BCM-7 with any other intervention(s). Outcomes are grouped according to the animal model in which they were analysed. As mentioned effect: analgesia, behavioural change, anaesthetic function, neurologic function on brain regions; Gut immune response: immunoglobulin concentration, histology of intestinal mucosa; Endocrine function: prolactin concentration, gastrin and somatostatin release). If a study investigated the primary outcome in more than one animal model, the chart shows a dot for each animal model (i.e., Hedner 1987 [19])

before, studies investigating BCM-7 focused mostly on its biological and metabolic properties such as neurological effects (acting as an opioid). Thus, we herein give an explorative summary about the outcomes that were investigated in included studies, without providing a detailed description of the results of each study. 
Briefly, the primary outcomes most analysed in studies investigating BCM-7 were related to neurological effects, such as behavioural change or analgesic effect. The relationship between neurological effects and BCM-7 relies on its ability to cross the blood-brain barrier and act as an opioid peptide. Its interaction with opioid receptors causes exorphin activity in the brain, which unfolds as e.g., behavioural change, analgesic effects, etc. Behavioural change was reported in rats in eight studies and included for example mother-oriented behaviour, learning, sleeping, or food intake behaviour [21, 32, 33, 35, 36, 39, 41, 42]. Most results showed that BCM-7 had indeed a stimulating effect on changing the behaviour of rats receiving this intervention compared to shorter fragments of BCM, saline solution, sterile water, or other equivalent solvent. An additional neurological outcome frequently investigated was analgesic effect, mainly as a pain reliever. Most studies compared this effect to other BCM fragments and investigated the opioid pathway for achieving the analgesic effect, including binding properties (e.g., affinity to opioid receptors). It was analysed in rats in five studies [18, 23, 29-31], in cockroaches in one study [34] and in broiler chickens in one further study [20]. Results showed that BCM-7 achieved significant pain relief in animals receiving the intervention. Many of the mentioned studies investigated additionally the effect of injecting naloxone as a specific opiate-receptor antagonist. They found that the BCM-7 effect was abolished by naloxone, confirming the opiate activity of BCM-7. One additional study reported that rats administered with BCM-7 had a stronger response in various brain regions, compared to rats in the control group [40]. At last, we identified one study reporting on BCM-7 as an anaesthetizing agent in rabbits and found that the intervention decreased respiratory frequency and depressed the central respiratory system, suggesting a positive effect to induce anaesthesia [19].

Eight studies reported on intermediate markers related to diabetes [43-47, 50-52]. From these, two studies found a stimulating effect on post-prandial insulin release in dogs after the intervention with either BCM-7 or a mixture of $\mathrm{BCM}$ fragments (incl. BCM-7), compared to shorter BCM fragments or saline solution $[44,52]$. Similarly, the study of Yin et al. reported lower blood glucose levels and increased insulin levels in rats fed BCM-7 with their normal diet compared to rats in the control group [45]; and Kim et al. reported that $\mathrm{BCM}$ mixture (incl. $\mathrm{BCM}-7$ ) lowered the responses of serum insulin in cows [50]. Furthermore, three studies found that BCM-7 had a protective effect on diabetic nephropathy in rats $[47,51]$ and on diabetic cardiomyopathy also in rats [43]; and one study reported less free-radicalmediated oxidative stress in the pancreas of rats fed BCM-7 compared to rats without the intervention [46].

Furthermore, results from five studies were grouped under outcomes related to endocrine function $[25,26,38$,
48]. Specifically, somatostatin release was investigated in three studies in dogs [25, 26], from which two studies found no effect of BCM-7 administration [25], and one study found a dose-dependent inhibition of somatostatin after the administration of BCM-7 [26]. In addition, Zong et al. found that BCM-7 modulated gene expression of the regulatory peptides from $\mathrm{G}$ and $\mathrm{D}$ cells in a rat population (by means of the paracrine action of somatostatin) [48]. One further study found an increased serum prolactin concentration in the blood of rats after BCM-7 [38], suggesting the beneficial effect of BCM-7 in lactation and in regulating the immune function.

Gut immune response was reported in two studies. Haq et al. found that oral administration of BCM-7 increased gut immune response in mice (measured with immunoglobulins and the concentration of various enzymes) [49], and similarly Yin et al. reported an improvement of intestinal mucosal immune decline (induced by aging) in mice administered BCM-7 [27].

Finally, four studies reported on further different outcomes. Chang et al. found increased growth performance with the administration of BCM-7 and described the involved mechanisms in broiler chickens [24]. Similarly, one study showed that BCM-7 stimulated DNA synthesis in new-born rats [37]. Furthermore, Wei et al. found no effect of BCM-7 on the heart rate of rats (acting as opioid agent) [22]. Finally, Zhang et al. found that BCM-7 was able to reduce sepsis in rats with induced kidney injury [28].

\section{Discussion}

\section{Principal findings}

The aim of this scoping review was to identify all potential health outcomes associated with A1 beta-casein (or BCM-7) in animal studies, to define the number and types of available animal studies, and to identify any gaps in the evidence base. To our knowledge, this is the first systematic scoping review on this topic in animal studies. We included and synthesized 42 eligible studies, most of them had an explorative character to investigate physiological properties of BCM-7 as an opioid peptide, for example on neurological functions. In this sense, BCM-7 was described to act as analgesic agent and to influence various metabolic processes. Only six included studies evaluated the effect of A1 milk (or A1 beta-casein) compared to A 2 milk (or A 2 beta-casein) and results suggest that A2 milk could have beneficial gastrointestinal effects compared to A1 milk. However, results for other outcomes e.g., outcomes related to CVD and diabetes seem inconclusive. We recently published a systematic review about the health effects of A1- and A2 beta-casein in humans and the results regarding gastrointestinal effects pointed in the same 
direction as results found in this scoping review in animal studies [5] and as the results from the systematic review of Brook-Taylor et al. [4]. Although effects from animal studies cannot be comparable to effects in humans, results from animal studies, together with further epidemiological and experimental studies (incl. in-vitro, biochemistry, pharmacological studies), could complement research for humans, particularly when the body of evidence remains uncertain as is the case in the A1- and A2 milk debate [4, 5]. For example, neurological effects of A1 beta-casein (or BCM-7) on schizophrenia, autism, or ADHS, where evidence is very limited and studies in humans are difficult to perform, could be expanded with results from animal research.

We identified 14 references which were not included in the scoping review due to the reasons mentioned above but results from these studies could influence the evidence map presented here. Additionally, effects of the consumption of A2 milk are increasingly being investigated parallel to the fast commercialization of A2 milk all over the world. Therefore, it will remain as an emergent topic for the next years and an update of this scoping review, or even a full systematic review would certainly be fundamental in the near future.

\section{Strengths and weaknesses of the scoping review}

To our knowledge, this is the first scoping review summarizing all available evidence on A1- and A2 beta-casein in animal studies. The summary of our results provides an overview of research performed so far in this field. Included studies were extremely heterogeneous in terms of the study population (e.g., healthy animals, but also animals with certain induced health issues were included), type of intervention and dose, and type of outcome measures; therefore, one of the main challenges during this scoping review was to synthesize available evidence in a comprehensive manner. Many of the included studies investigating BCM-7 as the intervention had as primary objective to explore biological effects and possible mechanisms of this opioid peptide. Thus, a clear healthrelated outcome was hardly identified. We are presenting the results separated by type of comparison (A1- vs. A2 milk; and BCM-7 vs. any other intervention) to provide results as clear and transparent as possible. Some important data to be considered when performing systematic reviews of animal studies were extracted but not presented in this scoping review (e.g., housing conditions, acclimatisation, etc.) to maintain a sound overview of this topic. For example, data about blinding of investigator or outcome assessor was extracted but no included study reported on this. To drive conclusions about this, further investigation is needed (e.g., contacting study authors to confirm if blinding was performed and how), but was not planned during this scoping review. Considering that this emerging topic is being actively investigated, not only in human studies but also in animal models, it is possible that new results relevant to this scoping review will emerge in the near future.

It is important to mention that the present work describes the scope of this topic without further critical evaluation of the included primary studies, e.g., no risk of bias assessment was performed. Therefore, conclusions about the effects of the intervention on health-related outcomes were not driven. Performing a systematic review would certainly provide a deeper insight into the evidence base on the health effects of A1- and A2 beta-casein.

\section{Conclusion}

Most studies investigated physiological properties of BCM-7 and only six studies compared the effects between A1- and A2 beta-casein. More studies on animal models would provide essential information to inform research gaps and results from these studies could eventually complement research for humans, particularly when the body of evidence remains uncertain as is the case in the A1- and A2 milk debate.

Supplementary Information The online version contains supplementary material available at https://doi.org/10.1007/s00394-021-02551-x.

Acknowledgements We would like to thank the team of the KErn (Kompetenzzentrum für Ernährung) for their invaluable input during the realization of the scoping review. We also thank Jasmin Zähringer, Gabriel Thorban, Philipp Kapp, and Jakub Morze for their contributions to this work; and also, to Edith Motschall for her help and expertise in developing the search strategy.

Author contributions DK, SL, SH, CR, and JJM had significant roles in the development of the scoping review question. DK, SL, and KB designed and conducted the search strategy. DK, SL and KB screened articles, extracted data, and conducted data synthesis. DK and SL drafted the first version of the manuscript, and all authors contributed to writing the final version of the manuscript.

Funding Open Access funding enabled and organized by Projekt DEAL. This project was funded through the Bavarian State Ministry for Food, Agriculture, and Forestry (7627.1-1/80).

Availability of data and materials The datasets supporting the conclusions of this article are included within the article (and its additional files 1, 2, and 3).

\section{Declarations}

Conflict of interest The authors have declared that no competing interests exist.

Open Access This article is licensed under a Creative Commons Attribution 4.0 International License, which permits use, sharing, adaptation, distribution and reproduction in any medium or format, as long as you give appropriate credit to the original author(s) and the source, provide a link to the Creative Commons licence, and indicate if changes were made. The images or other third party material in this article are included in the article's Creative Commons licence, unless indicated otherwise in a credit line to the material. If material is not included in 
the article's Creative Commons licence and your intended use is not permitted by statutory regulation or exceeds the permitted use, you will need to obtain permission directly from the copyright holder. To view a copy of this licence, visit http://creativecommons.org/licenses/by/4.0/.

\section{References}

1. de Noni I, FitzGerald RJ, Hannu K, et al (2009) Review of the potential health impact of $\beta$-casomorphins and related peptides. EFSA

2. ul Haq MR, Kapila R, Shandilya UK, Kapila S (2014) Impact of milk derived $\beta$-casomorphins on physiological functions and trends in research: a review. Int J Food Prop 17:1726-1741. https://doi.org/10.1080/10942912.2012.712077

3. Aune D, Norat T, Romundstad P, Vatten LJ (2013) Dairy products and the risk of type 2 diabetes: a systematic review and dose-response meta-analysis of cohort studies. Am J Clin Nutr 98:1066-1083. https://doi.org/10.3945/ajcn.113.059030

4. Brooke-Taylor S, Dwyer K, Woodford K, Kost N (2017) Systematic review of the gastrointestinal effects of A1 compared with A2 $\beta$-Casein. Adv Nutr Bethesda Md 8:739-748. https:// doi.org/10.3945/an.116.013953

5. Kullenberg de Gaudry D, Lohner S, Schmucker C et al (2019) Milk A1 beta-casein and health-related outcomes in humans: a systematic review. Nutr Rev. https://doi.org/10.1093/nutrit/ nuy063

6. Higgins JPT, Cochrane Collaboration (2019) Cochrane handbook for systematic reviews of interventions, Second edition. Wiley-Blackwell, Hoboken

7. SYstematic Review Center for Laboratory animal Experimentation (SYRCLE). https://www.radboudumc.nl/en/research/ departments/health-evidence/systematic-review-center-for-labor atory-animal-experimentation

8. Tricco AC, Lillie E, Zarin W et al (2018) PRISMA extension for scoping reviews (PRISMA-ScR): checklist and explanation. Ann Intern Med 169:467. https://doi.org/10.7326/M18-0850

9. Hooijmans CR, Tillema A, Leenaars M, Ritskes-Hoitinga M (2010) Enhancing search efficiency by means of a search filter for finding all studies on animal experimentation in PubMed. Lab Anim 44:170-175. https://doi.org/10.1258/la.2010.009117

10. de Vries RBM, Hooijmans CR, Tillema A et al (2011) A search filter for increasing the retrieval of animal studies in Embase. Lab Anim 45:268-270. https://doi.org/10.1258/la.2011.011056

11. Veritas Health Innovation, Covidence systematic review software. Melbourne, Australia

12. Beales P, Elliott R, Flohé S et al (2002) A multi-centre, blinded international trial of the effect of $\mathrm{A} 1$ and $\mathrm{A} 2 \beta$-casein variants on diabetes incidence in two rodent models of spontaneous Type I diabetes. Diabetologia 45:1240-1246. https://doi.org/10.1007/ s00125-002-0898-2

13. Chia JSJ, McRae JL, Enjapoori AK et al (2018) Dietary cows' milk protein A1 beta-casein increases the incidence of T1D in NOD mice. Nutrients. https://doi.org/10.3390/nu10091291

14. Haq MRU, Kapila R, Sharma R et al (2014) Comparative evaluation of cow $\beta$-casein variants (A1/A2) consumption on Th2-mediated inflammatory response in mouse gut. Eur J Nutr 53:1039-1049. https://doi.org/10.1007/s00394-013-0606-7

15. Kaminski S, Kostyra E, Cieslinska A, Fiedorowicz E (2011) Consumption of bovine $\beta$-casein variants (A1 or A2) does not affect basic hematological and biochemical indices. Milchwissenschaft 67:238-241

16. Barnett MPG, McNabb WC, Roy NC et al (2014) Dietary A1 $\beta$-casein affects gastrointestinal transit time, dipeptidyl peptidase- 4 activity, and inflammatory status relative to A2 $\beta$-casein in Wistar rats. Int J Food Sci Nutr 65:720-727. https://doi.org/ 10.3109/09637486.2014.898260

17. Tailford KA, Berry CL, Thomas AC, Campbell JH (2003) A casein variant in cow's milk is atherogenic. Atherosclerosis 170:13-19. https://doi.org/10.1016/S0021-9150(03)00131-X

18. Brantl V, Teschemacher H, Blaesig J (1981) Opioid activities of $\beta$-casomorphins. Life Sci 28:1903-1909. https://doi.org/10. 1016/0024-3205(81)90297-6

19. Hedner J, Hedner T (1987) $\beta$-Casomorphins induce apnea and irregular breathing in adult rats and newborn rabbits. Life Sci 41:2303-2312. https://doi.org/10.1016/0024-3205(87)90543-1

20. Panksepp J, Normansell L, Siviy S et al (1984) Casomorphins reduce separation distress in chicks. Peptides 5:829-831. https:// doi.org/10.1016/0196-9781(84)90030-5

21. Park M, Lin L, Thomas S et al (2004) The F1-ATPase $\beta$-subunit is the putative enterostatin receptor. Peptides 25:2127-2133. https:// doi.org/10.1016/j.peptides.2004.08.022

22. Wei ET, Lee A, Chang JK (1980) Cardiovascular effects of peptides related to the enkephalins and $\beta$-casomorphin. Life Sci 26:1517-1522. https://doi.org/10.1016/0024-3205(80)90275-1

23. Blass EM, Blom J (1996) $\beta$-Casomorphin causes hypoalgesia in 10-day-old rats: evidence for central mediation. Pediatr Res 39:199-203. https://doi.org/10.1203/00006450-199602000-00002

24. Chang WH, Zheng AJ, Chen ZM et al (2019) $\beta$-Casomorphin increases fat deposition in broiler chickens by modulating expression of lipid metabolism genes. Anim Int J Anim Biosci 13:777783. https://doi.org/10.1017/S1751731118002197

25. Schusdziarra V, Schick R, De La Fuente A (1983) Effect of $\beta$-casomorphins on somatostatin release in dogs. Endocrinology 112:1948-1951

26. Schusdziarra V, Specht J, Schick R (1983) Effect of morphine, leu-enkephalin and $\beta$-casomorphins on basal somatostatin release in dogs. Horm Metab Res 15:407-408. https://doi.org/10.1055/s2007-1018737

27. Yin H, Liu JJ, Yang D, Xu HQ (2019) Effect of $\beta$-casomorphin-7 on intestinal mucosal immunity in aged mice. Kafkas Univ Vet Fak Derg 25:689-696. https://doi.org/10.9775/kvfd.2018.21628

28. Zhang Z, Zhao H, Ge D et al (2019) $\beta$-Casomorphin-7 Ameliorates sepsis-induced acute kidney injury by targeting NF- $\mathrm{KB}$ pathway. Med Sci Monit 25:121-127. https://doi.org/10.12659/MSM. 912730

29. Dubynin VA, Maklakova AS, Nezavibat'ko VN et al (1992) Effects of systemically-administered beta-casomorphin-7 on nociception in rats. Biull Eksp Biol Med 114:284-286

30. Dubynin VA, Asmakova LS, Sokhanenkova NI et al (1998) Comparative analysis of neurotropic activity exorphins-derivatives of dietary proteins. Biull Eksp Biol Med 125:153-157

31. Dubynin VA, Malinovskaya IV, Ivleva YuA et al (2000) Delayed behavioral effects of $\beta$-casomorphin-7 depend on age and gender of albino rat pups. Bull Exp Biol Med 130:1031-1034. https://doi. org/10.1023/A:1002866911650

32. Dubynin VA, Ivleva YA, Stovolosov IS et al (2007) Effect of betacasomorphines on mother-oriented ("child's") behavior of white rats. Dokl Biol Sci Proc Acad Sci USSR Biol Sci Sect 412:1-4. https://doi.org/10.1134/s0012496607010012

33. Dubynin VA, Malinovskaia IV, Beliaeva IA, et al (2008) Delayed effect of exorphins on learning of albino rat pups. Izv Akad Nauk Ser Biol 53-60

34. Gritsai OB, Dubynin VA, Pilipenko VE et al (2000) The effects of beta-casomorphine-7 and naloxone of the locomotor defense response of the cockroach Periplaneta Americana to electrical stimulation. Dokl Biochem Proc Acad Sci USSR Biochem Sect 375:245-247. https://doi.org/10.1023/a:1026632108709

35. Lin L, Umahara M, York DA, Bray GA (1998) $\beta$-Casomorphins stimulate and enterostatin inhibits the intake of dietary fat in rats. 
Peptides 19:325-331. https://doi.org/10.1016/S0196-9781(97) 00307-0

36. Maklakova AS, Dubynin VA, Levitskaya NG et al (1993) The behavioral effects of beta-casomorphine-7 and its des-Tyr analogues. Byulleten Eksp Biol Meditsiny 116:155-158

37. Maslennikova NV, Sazonova EN, Timoshin SS (2008) Effect of $\beta$-casomorphin-7 on DNA synthesis in cell populations of newborn albino rats. Bull Exp Biol Med 145:210-212. https://doi.org/ 10.1007/s10517-008-0052-3

38. Nedvidkova J, Kasafirek E, Dlabac A, Felt V (1985) Effect of beta-casomorphin and its analogue on serum prolactin in the rat. Exp Clin Endocrinol 85:249-252

39. Sun Z, Cade JR (1999) A peptide found in schizophrenia and autism causes behavioral changes in rats. Autism 3:85-95. https:// doi.org/10.1177/1362361399003001007

40. Sun Z, Cade JR, Fregly MJ, Privette RM (1999) $\beta$-casomorphin induces Fos-like immunoreactivity in discrete brain regions relevant to schizophrenia and autism. Autism 3:67-83. https://doi. org/10.1177/1362361399003001006

41. Taira T, Hilakivi LA, Aalto J, Hilakivi I (1990) Effect of betacasomorphin on neonatal sleep in rats. Peptides 11:1-4. https:// doi.org/10.1016/0196-9781(90)90101-A

42. White CL, Bray GA, York DA (2000) Intragastric $\beta$-casomorphin1-7 attenuates the suppression of fat intake by enterostatin. Peptides 21:1377-1381. https://doi.org/10.1016/ S0196-9781(00)00281-3

43. Han DN, Zhang DH, Wang LP, Zhang YS (2013) Protective effect of $\beta$-casomorphin-7 on cardiomyopathy of streptozotocin-induced diabetic rats via inhibition of hyperglycemia and oxidative stress. Peptides 44:120-126. https://doi.org/10.1016/j.peptides.2013.03. 028

44. Schusdziarra V, Holland A, Schick R (1983) Modulation of postprandial insulin release by ingested opiate-like substances in dogs. Diabetologia 24:113-116. https://doi.org/10.1007/BF00297392
45. Yin H, Miao J, Zhang Y (2010) Protective effect of $\beta$-casomorphin-7 on type 1 diabetes rats induced with streptozotocin. Peptides 31:1725-1729. https://doi.org/10.1016/j.peptides. 2010.05.016

46. Yin $\mathrm{H}$, Miao J, Ma C et al (2012) $\beta$-Casomorphin-7 cause decreasing in oxidative stress and inhibiting NF- $\mathrm{\kappa B}-\mathrm{iNOS}-\mathrm{NO}$ signal pathway in pancreas of diabetes rats. J Food Sci 77:C278-282. https://doi.org/10.1111/j.1750-3841.2011.02577.x

47. Zhang W, Miao J, Ma C et al (2012) $\beta$-Casomorphin-7 attenuates the development of nephropathy in type $i$ diabetes via inhibition of epithelial-mesenchymal transition of renal tubular epithelial cells. Peptides 36:186-191. https://doi.org/10.1016/j.peptides.2012.05. 022

48. Zong YF, Chen WH, Zhang YS, Zou SX (2007) Effects of intragastric beta-casomorphin-7 on somatostatin and gastrin gene expression in rat gastric mucosa. World J Gastroenterol 13:2094 2099. https://doi.org/10.3748/wjg.v13.i14.2094

49. Haq MRU, Kapila R, Saliganti V (2014) Consumption of $\beta$-casomorphins-7/5 induce inflammatory immune response in mice gut through Th2 pathway. J Funct Foods 8:150-160. https:// doi.org/10.1016/j.jff.2014.03.018

50. Kim TG, Choung JJ, Wallace RJ, Chamberlain DG (2000) Effects of intra-abomasal infusion of $\beta$-casomorphins on circulating concentrations of hyperglycaemic insulin and glucose in dairy cows. Comp Biochem Physiol Mol Integr Physiol 127:249-257. https:// doi.org/10.1016/S1095-6433(00)00267-1

51. Zhang W, Miao J, Wang S, Zhang Y (2013) The protective effects of beta-casomorphin-7 against glucose -induced renal oxidative stress in vivo and vitro. PLoS ONE. https://doi.org/10.1371/journ al.pone. 0063472

52. Schusdziarra V, Schick A, de la Fuente A et al (1983) Effect of beta-casomorphins and analogs on insulin release in dogs. Endocrinology 112:885-889. https://doi.org/10.1210/endo-112-3-885 